\title{
Lexical Diachronic Semantic Maps
}

\author{
Thanasis Georgakopoulos (athanasios.georgakopoulos@ulg.ac.be) \\ Stéphane Polis (s.polis@ulg.ac.be) \\ University of Liège - F.R.S.-FNRS
}

International Summer School on Typology and Lexicon (TyLex), Moscow, 2-7 September, 2017

\section{INTRODUCTION}

The Project: Le Diasema

Main objectives

To incorporate the diachronic dimension into semantic maps of content words

To create an online platform for automatically plotting diachronic semantic maps based on polysemy data from the languages of the world

- To extend the method so as to also include information about the cognitive and cultural factors behind the development of the various meanings

\section{What are semantic maps?}



Webpage: http://web.philo.ulg.ac.be/lediasema/

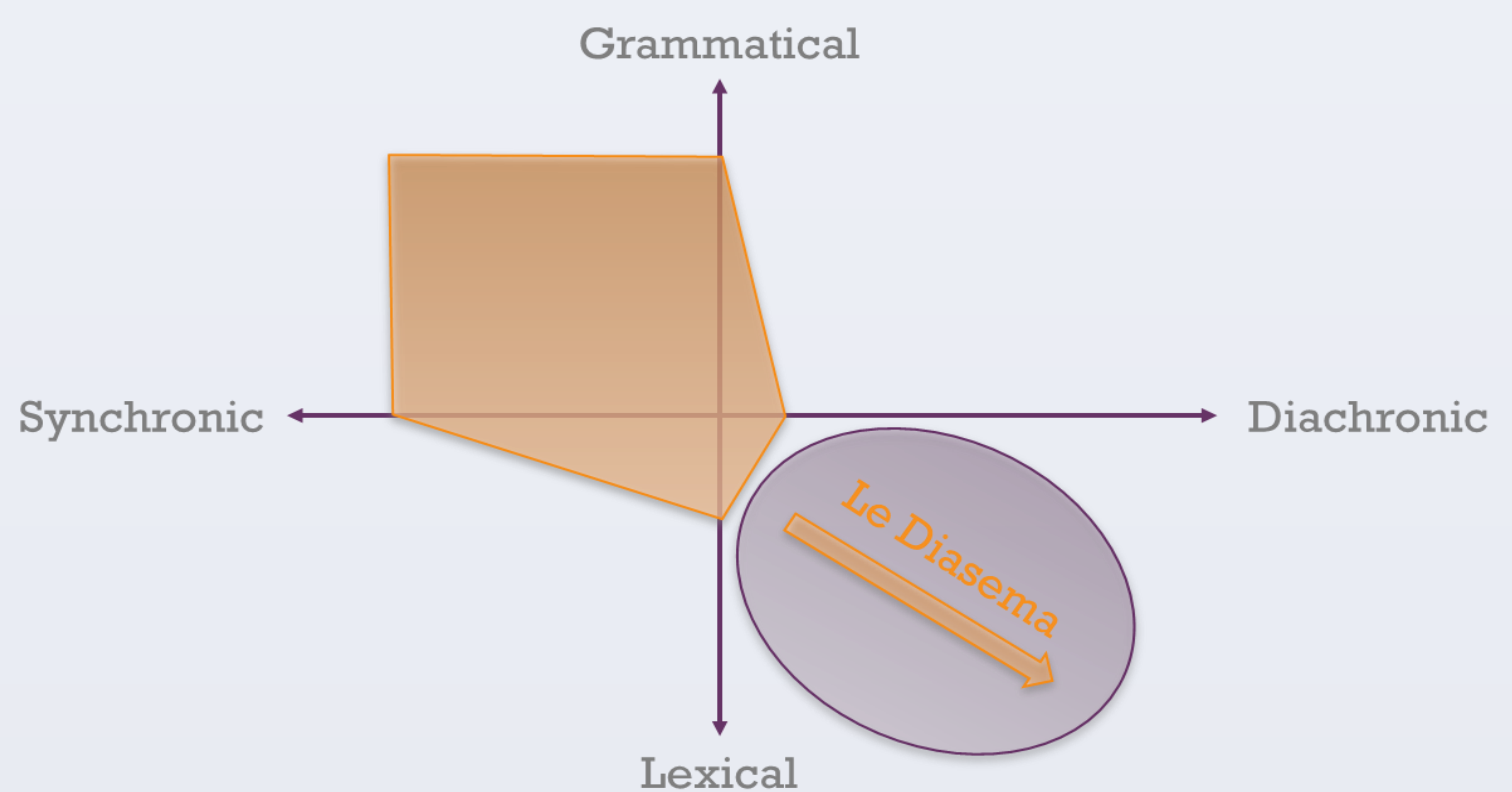

'A semantic map is a geometrical representation of functions (...) that are linked by connecting lines and thus constitute a network' (Haspelmath, 2003). It constitutes a 'model of attested variation' (Cysouw, 2007).

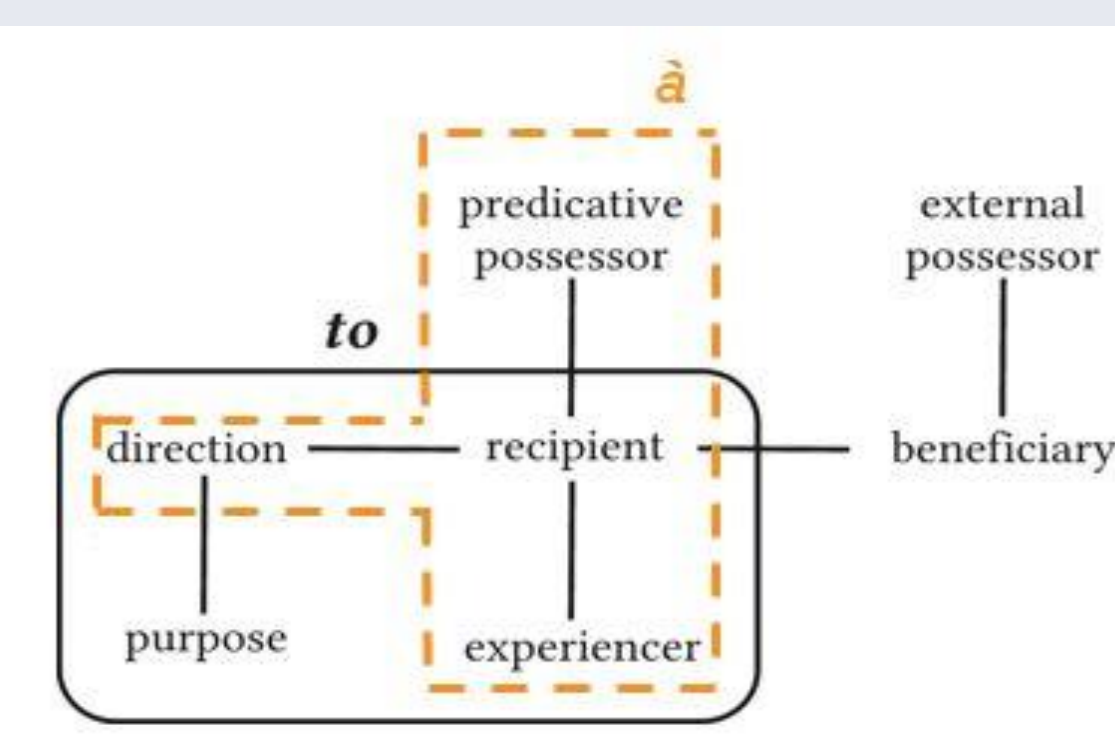

Figure 1. A semantic map of typical dative functions,

with the boundaries of English to and French $a$ (based on Haspelmath, 2003: 213, 215)

\section{- Meaning distinctions are based on cross-linguistic evidence and designed to have cross-linguistic validity \\ - They combine the onoma- siological and the sema- siological perspective \\ - Multifunctionality. No commitment to a particular claim about conventiona- lization of senses}

\section{AUtomatic PLOTTING}

'[I]deally (...) it should be possible to generate semantic maps automatically on the basis of a given set of data' (Narrog \& Ito, 2007: 280)

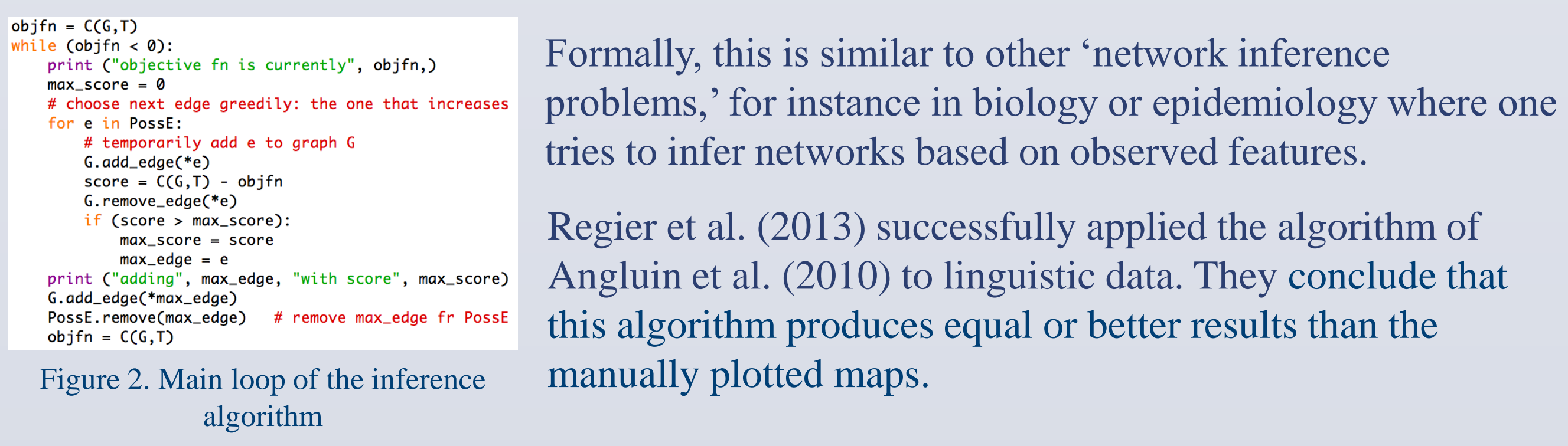

\section{VISUALIZATION TOOLS}

Visualization techniques and actual semantic analysis will be inseparable in the future of the semantic map model (cf. Malchukov, 2010: 177)


CASE STUDY: THE SEMANTIC EXTENSION OF TIME-RELATED

LEXEMES IN ANCIENT EGYPTIAN AND ANCIENT GREEK

\begin{tabular}{|ll|} 
1. Choose the concepts: time-related concepts in the Swadesh & Why? \\
200-word list (Swadesh, 1952: 456-457): & - Universality \\
A. DAY/DAYTIME; B. NIGHT; C. YEAR & - Stability \\
\hline
\end{tabular}

\section{CROSSLINGUISTIC POLYSEMY PATTERNS}

2. Identify in CLICS (List et al., 2014) the main polysemy patterns attested for these three meanings

- E.g., DAY/DAYTIME: CLOCK/TIMEPIECE, HOUR, SEASON, SUN, TIME, WEATHER

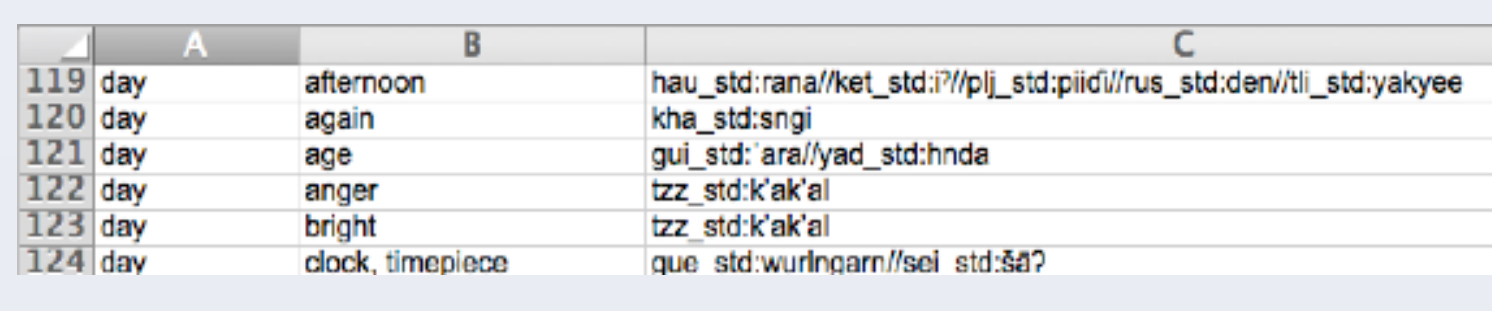

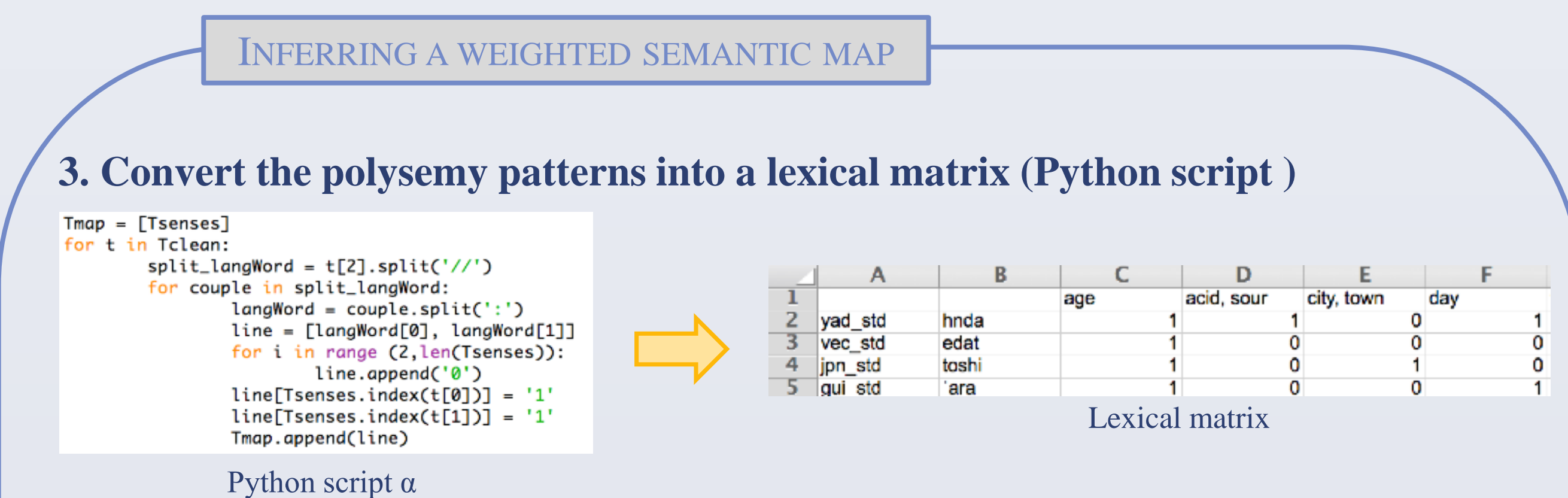

4. Plot a weighted semantic map with an adapted version of the algorithm suggested by Regier et al. (2013) that computes weighted edges (Python script $\beta$ )

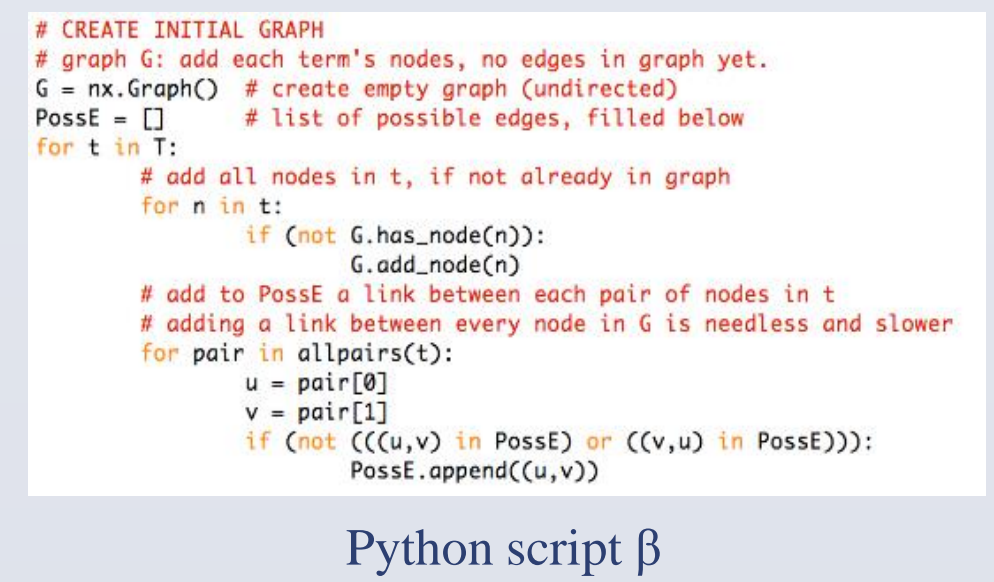

5. Visualize the crosslinguistic semantic map of time-related senses

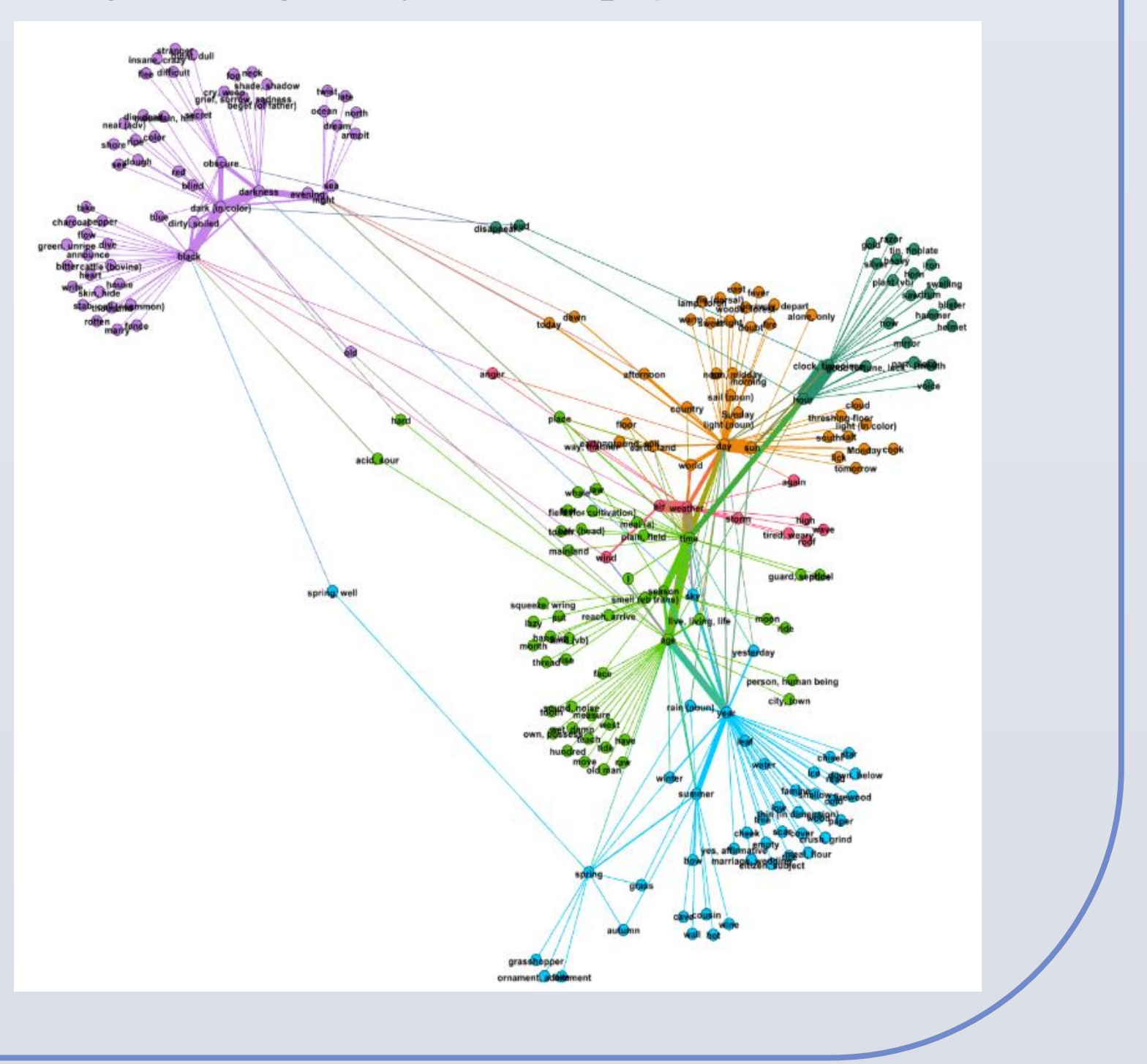

Figure 6. Full semantic map for ime-related meanings, visualize with modularity analysis
(Blondel et al., 2008) in Gephi

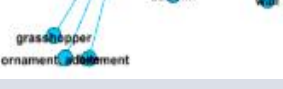

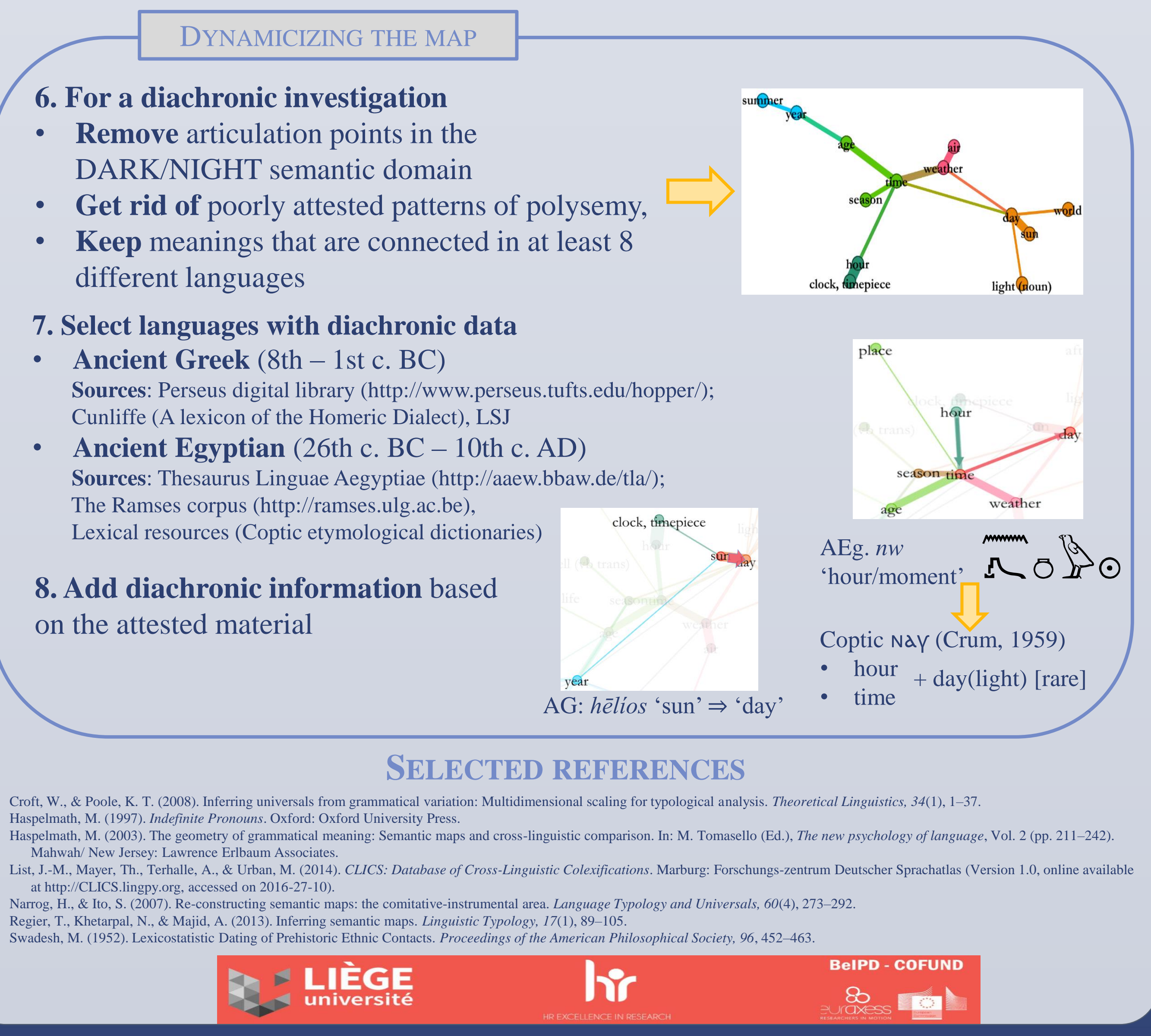

